\title{
OS ESTUDOS CULTURAIS: O ESPAÇO DA INSATISFAÇÃO DO SUJEITO
}

\author{
Maria Regina Barcelos Bettiol \\ Maria Regina Bettiol é professora Substituta de Teoria Literária da Universidade Federal do Rio Grande do Sul
}

RESUMO: Cet essai porte sur le changement épistémologique provoqué par la théorie des études culturelles (cultural studies) en prenant en compte certaines implications pédagogiques de ce changement au sein de l'enseignement universitaire. Les études culturelles ne sont pas présentées ici comme une menace mais comme une forme de pédagogie alternative qui doit être ajoutée aux savoirs déjà établis. En somme, une pédagogie qui doit être entendue comme espace d'ouverture de nouvelles énonciations.

PALAVRAS-CHAVE: Pedagogia. Sujeito. Política.

Cuando ya ténia respuestas a la vida, me cambiaron las preguntas. Velha inscrição encontrada em um muro de Quito

\begin{abstract}
Delante de la imposibilidad de reformular el orden impuesto, se buscan vías diagonales como prácticas transformadoras. Hay aún otro modo en que la oblicuidad de los circuitos simbólicos permite repensar los vínculos entre cultura y poder. La búsqueda de mediaciones, de vías diagonales para gestionar los conflictos, da a las relaciones culturales un lugar prominente en el desenvolvimiento político. Néstor Garcia Canclini
\end{abstract}

Parece-me perfeita a velha inscrição do muro de Quito - Quando tinha respostas à vida, me renovaram as perguntas - para exemplificar os efeitos provocados pelos estudos culturais dentro da academia e da sociedade como um todo. Quando pensávamos conhecer as respostas, os estudos culturais nos lançaram uma implacável sucessão de perguntas, nos obrigaram a relocalizar nossa escritura, nos convidaram a imaginar diferentes mapas culturais. Mas o grande desafio lançado foi, sem dúvida alguma, o pedagógico. A mudança epistemológica alavancada pelos estudos culturais exige uma pedagogia que consiga contemplar uma nova noção de sujeito não a de sujeito universal tal qual nós conhecemos - mas de um sujeito agregador de identidades e atravessado por múltiplas subjetividades. Neste breve ensaio, discutirei algumas implicações pedagógicas ocasionadas por essa mudança epistemológica, que são ao meu ver, de fundamental relevância para legitimar o lugar dos estudos culturais dentro das práticas acadêmicas e sua inegável contribuição aos estudos literários.

Em seu famoso livro O Cânone Ocidental: Os Livros e a Escola do Tempo - que me serve de pretexto para discutir determinadas questões referentes ao estudos culturais - o crítico e ensaísta norte-americano Haroldo Bloom inclui os defensores dos estudos culturais numa escola que ele denomina de a Escola do Ressentimento (2001, p. 13), os acusa de tentar acabar com o cânone ocidental, de desconhecer o que ele chama de excelência literária das obras clássicas. Essa opinião de Bloom é compartilhada por alguns teóricos dos estudos literários, entre eles, alguns brasileiros. Em primeiro lugar, não empregaria a palavra ressentimento que remete a um sentimento de mágoa. Não se trata de uma simples mágoa por ter sido excluído ou de um recalque social, a questão é mais complexa. O estranhamento, a não identificação geram naturalmente um processo de insatisfação. Esse problema, a meu ver, reflete muito mais do que questões políticas, de classe, gênero ou etnia, ele passa também pelo ordem do metafísico. Vou mais além, a insatisfação já nasce enraizada em todo ser humano e a literatura sempre registrou as angustias, sempre foi palco de discussão do descontentamento humano. Aliás, o ato de escrever já é por si só um ato de insatisfação, que não foi inaugurado pelos estudos culturais, são os insatisfeitos que escrevem, os que sentem um enorme desejo de transformar o mundo em que vivem.

Os estudos culturais denominados por Stuart Hall (2003, p.11) como uma forma de pensar a cultura, melhor seria acrescentar os vínculos entre cultura e poder, nos revelam a insatisfação do(s) sujeito(s), da sua luta pelo espaço de representação dentro da sociedade. Os estudos culturais deixam claro a necessidade, para aqueles que exercem o oficio da escritura, de negociar o espaço de enunciação, de definir o papel do sujeito dentro das relações transformadoras. Afinal, é mais do que sabido que quem maneja a pluma maneja o poder, a palavra e a sua força fundacional (ACHUGAR, 1998, p. 27). O ato de escrever é um ato de poder que exige um comprometimento ético por parte de quem escreve. De certa forma, isso se torna mais evidente dentro dos estudos culturais onde o intelectual tem o compromisso de anunciar as suas afiliações doutrinárias, de diferenciar o trabalho intelectual do acadêmico:

Volto à seriedade tremenda do trabalho intelectual. É um assunto tremendamente sério. Volto às distinções críticas entre o trabalho intelectual e o trabalho acadêmico: sobrepõem-se, tocam-se, nutrem-se um ao outro, fornecem os meios para se fazer um ao outro. Contudo, não são a mesma coisa (...) Volto à teoria e à política, à política da teoria. Não a teoria como vontade de verdade, mas a teoria como um conjunto de conhecimentos 
que têm de ser debatidos de um modo dialógico. Mas também como prática que pensa sempre a sua intervenção num mundo em que faria alguma diferença, em que surtiria algum efeito. Enfim, uma prática que entende a necessidade da modéstia intelectual. Acredito haver toda a diferença no mundo entre a compreensão da política do trabalho intelectual e a substituição da política pelo trabalho intelectual. (HALL, 2003, p. 216-217).

A Escola da Insatisfação, vou nomeá-la assim, com suas propostas diversificadas produziu novas formas de conhecimento e como toda teoria teve o poder de intervir na sociedade. Quando falamos em estudos culturais não podemos reduzi-los a um pluralismo simplista, a um vale tudo, colocar "todos os teóricos desse campo no mesmo saco" como fez Bloom. Há diferentes posicionamentos e metodologias dentro dos estudos culturais:

Os estudos culturais abarcam discursos múltiplos, bem como numerosas histórias distintas. Compreendem um conjunto de formações com suas diferentes conjunturas e momentos no passado. Gostaria de insistir na variedade de trabalhos inerentes aos estudos culturais (...) Os estudos culturais tiveram uma grande diversidade de trajetórias: muitas seguiram e seguem percursos distintos no seu interior; foram construídos por um número de metodologias e posicionamentos teóricos diferentes, todos em contenção uns com os outros. (HALL, 2003, p. 201).

Cabe esclarecer, contudo, como se efetuam as transformações dentro da lógica dos estudos culturais. As transformações se efetuam através de um desafio do poder publico, de uma transgressão da tradição, de uma crítica à ordem operante. Em outras palavras, escrever significa abrir espaço: Todo lugar criado é abertura de espaço. E toda pessoa que escreve por profissão vive em busca de espaço (MORICONI, 1999, p. 80). Os estudos culturais conseguiram abrir "fendas" dentro do discurso oficial, desvelar as práticas culturais que norteiam nossas relações, denunciar como os bens simbólicos são trabalhados, manipulados, inculcados em nossa formação cultural, como essas práticas de representação constituem sujeitos humanos.

A expressão utilizada por Nestor Garcia Canclini (1990, p. 326) - manifestação do poder oblíquo - pode ser relacionada à estratégia empregada pelos estudos culturais isto é, mesmo não conseguindo reformular a ordem imposta, os teóricos dos estudos culturais optaram por uma leitura oblíqua da sociedade, por um "ataque" por vias diagonais, por gerenciar os conflitos e repensar as relações culturais através de uma transgressão, de um desvio, sobretudo da linguagem, rompendo com as representações tradicionais de poder.

Outro ponto bastante polêmico sustentado por Bloom é o da excelência literária. Como se esse conceito fosse isento de qualquer tipo de determinação ideológica. Uma das principais contribuições dos estudos culturais aos estudos literários foi justamente mostrar como as idéias de excelência literária funcionam dentro das instituições:

Excelência literária nunca determinou o que é estudado (...) O que mudou é um interesse na escolha de obras que representem uma gama de experiências culturais e também uma gama de formas literárias (...) A excelência literária foi historicamente comprometida por critérios não - literários, envolvendo raça e gênero (...) Ela cultua interesses e propósitos culturais particulares como se fossem o único padrão de avaliação literária. (CULLER, 2001, p. 54-55)

A excelência literária sempre esteve, ainda que de forma camuflada, ligada à representatividade cultural. O próprio Bloom escolheu sua lista de obras clássicas baseado nos valores do cânone eurocêntrico. Houve mudanças, que não podem ser ignoradas, nas condições de produção intelectual, artística, no papel da cultura, apenas para mencionar as mais visíveis. Saberes novos exigem modelos diferentes, modelos que precisam ser gerenciados de outra forma. Os estudos culturais apesar de todos os rumores apocalípticos, revigoraram o cânone proporcionaram, através de suas inúmeras abordagens, um novo impulso e percepção dos estudos literários. Se existe uma utopia dentro dos estudos literários é o da excelência literária, uma noção que parece sólida mas quando nos aproximamos desmancha no ar:

Mas os próprios estudos literários nunca foram unificados em torno de uma única concepção daquilo que estavam fazendo, fosse tradicional ou não; e, desde o advento da teoria, os estudos literários são uma disciplina contestada e controversa, em que todos os tipos de projetos, tratando tanto das obras literárias como das não-literárias, brigam por atenção (...) os estudos literários podem ganhar quando a literatura é estudada como uma prática cultural específica e as obras são relacionadas a outros discursos. (CULLER, 2001, p. 52)

Os estudos culturais em sua reflexão sobre a dialética do poder e do conhecimento evidenciaram, ainda mais, a luta das obras literárias versus não literárias, luta esta que já existia no interior dos estudos literários. Rompendo com velhas correntes do pensamento, os estudos culturais expandiram o arco das questões que as obras literárias podem responder transformando a natureza das questões propostas. Não há, portanto, necessariamente um conflito entre os estudos culturais e literários:

O que importa são as rupturas significativas em que velhas correntes de pensamento são rompidas, velhas constelações deslocadas, e elementos novos e velhos são reagrupados ao redor de uma nova gama de premissas e temas. Mudanças em uma problemática transformam significativamente a natureza das questões propostas, as formas como são propostas e a maneira como podem ser adequadamente respondidas. (HALL, 2003, p. 131).

Mas retornando a questão dos modelos, as teorias contemporâneas, entre elas os estudos culturais, apontam para falência de dois modelos de gestão do saber: o positivista e o iluminista. O primeiro, com a sua demarcação ilusória das fronteiras do saber tornou-se obsoleto e inviável num mundo em que justamente o cruzamento das fronteiras demonstra, mais do que nunca, a correspondência entre os ramos do conhecimento. Os 
estudos culturais, por sua abertura interdisciplinar, estão mais sintonizados com os projetos desses novos saberes que se formam. O segundo modelo, o iluminista, foi posto em xeque pelo que chamamos de desconstrução das metafísicas do individuo:

O individuo critico que os descontentes com a barbárie pós-moderna querem salvar calca-se na idéia de sujeito cognitivo universal a priori, um ponto arquimediano, anterior a tal trabalho desconstrutivo, sujeito teórico, abstraído dos lugares históricos em que se efetivam concretamente os processos de subjetivação. E, o fato é que todos, ou quase todos os magníficos monumentos high modernist, operaram no sentido de mostrar a inadequação, os limites, a ilusão representada pelo sujeito cognitivo universal. (MORICONI, 1999, p. 81)

Os estudos culturais denunciam a falácia do sujeito cognitivo universal discutindo o caráter problemático da identidade, a maneira como as identidades são formadas, transmitidas, a dificuldade dos grupos minoritários em se identificarem com a cultura dominante mostrando claramente a cultura como uma construção ideológica que sofre mudanças. Os estudos culturais acabam com qualquer pretensão de se falar em nome do universal apontando nosso discurso como uma prática cultural localizada. Assim, falar de um sujeito universal não faz mais sentido dentro de um mundo que tende à pluralização de discursos e práticas culturais, que tende a formar, cada vez mais, sujeitos diaspóricos:

O problema a ser enfrentando daí para frente é que o espaço deixado por esse sujeito (...) passa a ser agora visado por uma pluralidade de processos de subjetivação que se caracterizam por serem externos, estranhos, estrangeiros em relação ao drama histórico concreto dentro do qual adquirira sentido o sujeito universal. A própria supervalorização da idéia de crítica precisa ser relativizada, pois o que os sujeitos plurais proliferantes da pós-modernidade fazem não é propriamente criticar o espaço do sujeito universal e sim superpor-lhe novos espaços. E uma lógica da agregação mais do que da negação. Agregam-se novos sujeitos sociais, relacionados a novos modos de subjetivação individual e grupal, explodindo de fora para dentro o espaço público harmônico que conferia a base simultaneamente ideal e histórica do sujeito universal (...) A crise do sujeito universal é um problema da idade dos nossos avós. Nosso problema é o da proliferação e superposição de sujeitos diaspóricos (MORICONI, 1999, p. 82).

O tipo de leitura alternativa proposta pelos estudos culturais tem como foco de investigação a formação desses sujeitos diaspóricos. Como bem observa Moriconi $(1999$, p. 82$)$ não se pode ler essas novas textualidades orientados pelos critérios do alto modernismo, pelo olhar da pedagogia iluminista uma vez que a natureza do saber, agora ligada à práxis cotidiana, foi modificada.

Todavia, a crítica de Bloom é muito pertinente no que diz respeito a um grupo que se alojou no coração dos estudos culturais, sobretudo de orientação norte-americana, conhecido como grupo PC ou do "politicamente correto". A trajetória desse grupo é internacionalmente conhecida pela sua detestável patrulha ideológica, grupo este que nasceu com ares pseudo-democráticos mas que pelas suas ações se revelou autoritário e defensor de um totalitarismo dos mais tacanhos. Nessa pedagogia se substitui a política pelo trabalho intelectual, as reivindicações marcham sob uma única bandeira, procura-se transferir posicionamentos intactos de uma conjuntura para outra, tenta-se cristalizar esses posicionamentos como se fossem imutáveis. Para o PC, conhecimento válido é o transmitido pela própria experiência como se a experiência não tivesse limites e as idéias fossem determinadas unicamente pela experiência. Essas questões preocupam alguns teóricos dos estudos culturais, entre eles Stuart Hall, que não concordam com essa pedagogia proposta pelo PC:

Sempre se deve ter consciência da forma específica da própria existência. As idéias não são simplesmente determinadas pela experiência; podemos ter idéias fora da própria experiência. Mas precisamos reconhecer também que a experiência tem uma forma, e se não refletirmos bastante sobre os limites da própria experiência (e a necessidade de se fazer um deslocamento conceitual, uma tradução, para dar conta das experiências que pessoalmente não tivemos), provavelmente vamos falar a partir do continente da própria experiência, de uma maneira bastante acrítica. Eu acho que é isso acontece nos estudos culturais hoje. (HALL, 2003, p. 17).

Outro aspecto interessante, e ao mesmo tempo surpreendente, é que a pedagogia PC ignora ou finge ignorar que a cultura trabalha através de suas textualidades operando deslocamentos de sentido, que ocorre um processo de descentralização da linguagem e conseqüentemente da significação:

A metáfora do discursivo, da textualidade, representa um adiamento necessário, um deslocamento, que acredito estar sempre implícito no conceito da cultura. Se vocês pesquisam sobre a cultura, ou se tentaram fazer pesquisa em outras áreas, verdadeiramente importantes e, não obstante, se encontraram reconduzidos à cultura, se acontecer que a cultura lhes arrebate a alma, têm de reconhecer que irão sempre trabalhar numa área de deslocamento. Há sempre algo descentrado no meio cultural (the medium of culture), na linguagem, na textualidade, na significação; há algo que constantemente escapa e foge à tentativa de ligação, direta e imediata, com outras estruturas (HALL, 2003, p. 211-212).

A tensão entre questões políticas e teóricas é permanente e continuará existindo, a prática intelectual representa uma forma de intervenção política. A teoria dos estudos culturais deve ter consciência dos seus limites, dificilmente conciliará teoria com projetos políticos pois trabalha com a linguagem e seus deslocados. Concordo com Roland Barthes (1979, p. 17) quando ele diz que as forças de liberdade que residem na literatura não dependem da pessoa civil ou do compromisso político do escritor mas do trabalho de desvio que ele exerce sobre a linguagem. 
Para concluir, penso os estudos culturais não como um projeto político mas como uma teoria que trouxe discernimento à prática política, como um fenômeno intertextual complexo que nos revelou as intertextualidades dos textos em suas posições institucionais, os textos como inegáveis fontes de poder, vejo como mais uma ferramenta teórica que nos permite fazer um exame dos papéis culturais dos quais a literatura é investida, as identidades que constitui. Enfim, concebo os estudos culturais como uma pedagogia alternativa, que não veio ameaçar, mas se agregar aos saberes já institucionalizados abrindo espaço para novos conhecimentos, novas formas de enunciação.

\section{REFERÊNCIAS BIBLIOGRÁFICAS}

ACHUGAR, Hugo. La fundación por la palabra. Montevideo: FHCE/Universidad de la República,1998, p. 27.

BARTHES, Roland. Aula. Trad. Leila Perrone-Moisés. SP: Cultrix, 1959, p. 17.

BLOOM, Harold. O cânone ocidental: os livros e a escola do Tempo. RJ: Objetiva, 2001, p. 13.

CANCLINI, Nestor Garcia. Culturas híbridas, estrategias para entrar y salir de la modernidad. México: Grijalbo, 1990, p. 326.

CULLER, Jonathan. Teoria literária: uma introdução. SP: Beca, 1999.

HALL, Stuart. Da diáspora: identidades e mediações culturais. ORG. Liv Sovik. Trad. Adelaine Resende. [et al] BH: UFMG,2003.

MORICONI, Ítalo. Qualquer coisa fora do tempo e do espaço: poesia, literatura, pedagogia da barbarie. IN: Leituras do Ciclo. ORGS: Ana Luiza Andrade, Maria L. Barros e Raul Antelo. Florianópolis: ABRALIC, 1999. 